\title{
Ontogenesis, bunion, cyst, atrium: the keratocystic odontogenic tumefaction
}

\author{
Anubha Bajaj* \\ Consultant Histopathologist at A.B. Diagnostics, Rajouri Garden, New Delhi, India
}

\section{Short communication}

Odontogenic Keratocyst (OKC) was initially described in the mid- $20^{\text {th }}$ century [1]. The world health organization (WHO) has designated it as a Keratocystic Odontogenic Tumour (KCOT) [2]. It is elucidated as a benign uni-cystic or multi-cystic, intra-osseous tumour of odontogenic ancestry with a distinctive lining of parakeratinized stratified squamous epithelium and an inherent capacity for aggressive, infiltrative behaviour. The lesion appears gradually, is locally invasive with a precipitous reoccurrence and a lack of distant metastasis or bone destruction [2]. A male preponderance and an age range of 20 to 40 years may be delineated. In concordance with the WHO classification, the lesion Odontogenic Keratocystic Tumour (OKT) appropriately depicts the nature of the neoplasm and is hypothesized to originate from the remnants of a dental lamina.

\section{Analysis and attributes}

A multi-locular or a unilocular cyst with a well delineated border is demonstrated on X-ray. The average tumour surface area is described at an estimated $14 \mathrm{~cm}^{2}$ and ranges from 0 to $15 \mathrm{~cm}^{2}$ on radiography. Majority of the clinical presentations and subsequent recurrences may be encountered within the specified parameters of the lesions [3]. An estimated $11 \%$ of the jaw cysts are constituted by the keratocystic odontogenic tumour (KCOT). The lesions may predominantly be situated in the mandible, particularly the posterior body and ramus $[4,5]$. The cystic lesions may invariably be centred in the bone, although peripheral KCOT are generally infrequent [6-8]. OKC's are usually asymptomatic and are generally detected on plain radiographs. Massive lesions may produce inadequate spacing of the teeth and an involuntary discharge of the cystic contents in the oral cavity. Dental root reabsorption may be rare, except in instances of the Nevoid Basal Cell Carcinoma Syndrome (NBCCS) [3]. Concomitant infection, a traumatic aetiology and cystic exudation may elucidate pain, cyst distension, a localized tissue destruction and cystic aggregation especially with the accompanying NBCCS or Gorlin- Goltz Syndrome $[9,10]$.

The distinction of the lesion from a gingival cyst or a malignancy includes conditions such as the lateral periodontal cyst, traumatic bone cyst, central giant cell tumour, radicular cyst, ameloblastoma and adenomatoid tumour of the jaw [3]. HISTOPATHOLOGICAL examination of the lesion (KCOT) depicts a conventional thin, uniform stratified squamous epithelial lining with prominent parakeratosis. Inflammation is absent. The cuboidal or columnar basal layer is preponderantly palisading. Cytological delineation of KCOT is feasible. The tumours commonly reoccur at an estimated $25 \%$ to $60 \%$ and the reappearance amplifies to roughly $82 \%$, in combination with NBCCS [11-13]. Nevoid Basal Cell Carcinoma Syndrome (NBCCS) is also constituted by the appearance of a nevoid basal cell carcinoma, bifid ribs, calcification of the falx cerebri , frontal bossing, multiple epidermoid cysts and medulloblastoma, besides the keratocystic odontogenic tumour (KCOT) [14].The reoccurrence of keratocystic odontogenic tumour(KCOT) has been surmised as: a)A fragmentary elimination of the cyst lining, b)the propagation of a fresh tumour from the satellite cysts (or surgical remnants of odontogenic rests) and c) the evolution of a distinct tumefaction (KCOT) in a contiguous zone, which may be construed as a recurrence [15]. The variation in the reoccurrences are attributed to the variable follow up, the surgical strategies and the consolidated case figures (Figures 1-11) [16]. The tumour re-appearances are significant following 5- 7 years of therapy, thereby necessitating an extensive follow up.

\section{ODONTOGENIC CYSTS}

Primordial cyst
Dentigerous cyst (follicular)
Radicular cyst (periodontal, dental,
periapical, inflammatory, infected)
Lateral periodontal cyst
Residual cyst
Odontogenic keratocyst
Calcifying odontogenic cyst (Gorlin cyst)

Figure 1. Sub-classification of the odontogenic cysts

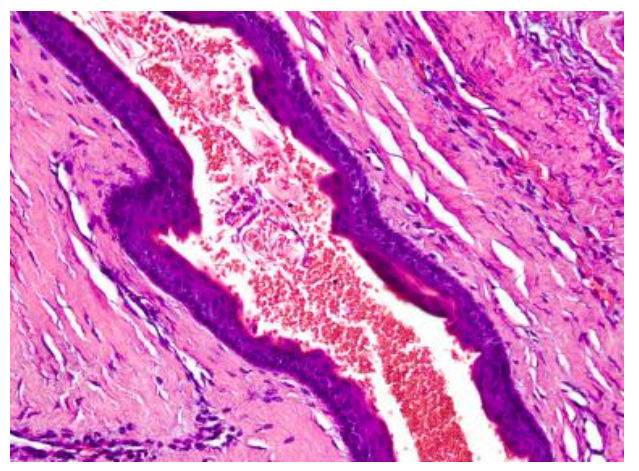

Figure 2. Odotogenic Keratocyst- with compressed stratified squamous lining

${ }^{*}$ Correspondence to: Anubha Bajaj, Consultant Histopathologist at A.B Diagnostics, Rajouri Garden, New Delhi, India, Tel: +00911125117399; +00919811693956; E-mail: anubha.bajaj@gmail.com; anubha.bajaj@yahoo.com

Received: June 12, 2018; Accepted: June 25, 2018; Published: June 29, 2018 


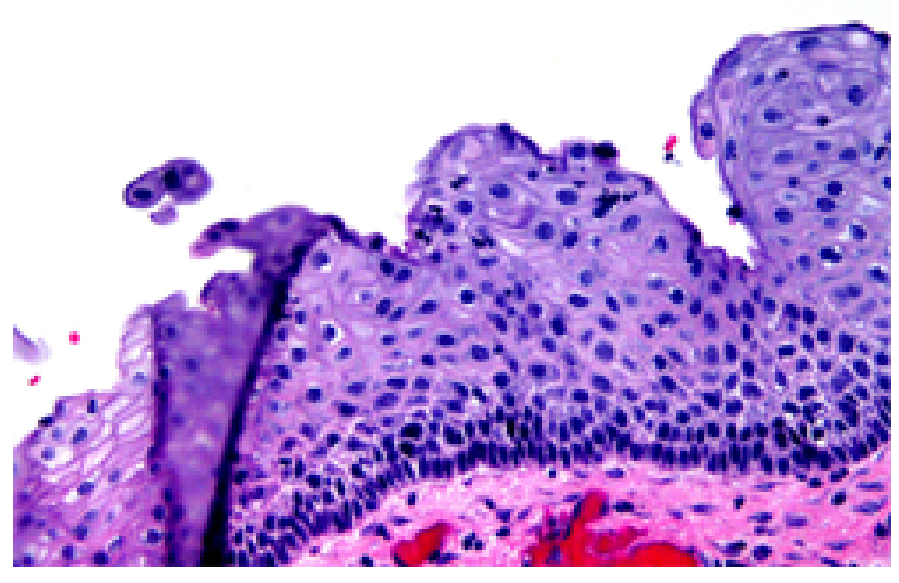

Figure 3. Stratified epithelium with parakeratinization

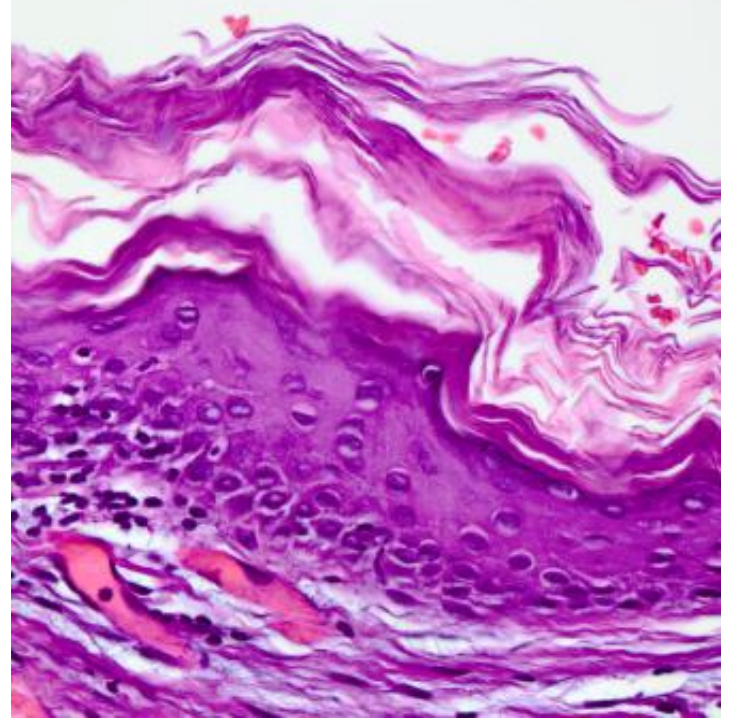

Figure 4. Keratocyst with hyper-keratosis

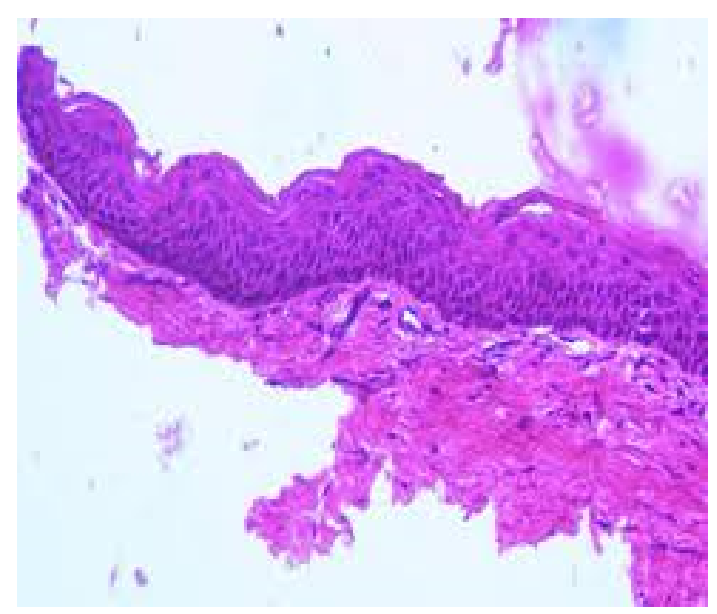

Figure 5. Keratocyst-Prominent stratified epithelium with orthokeratosis

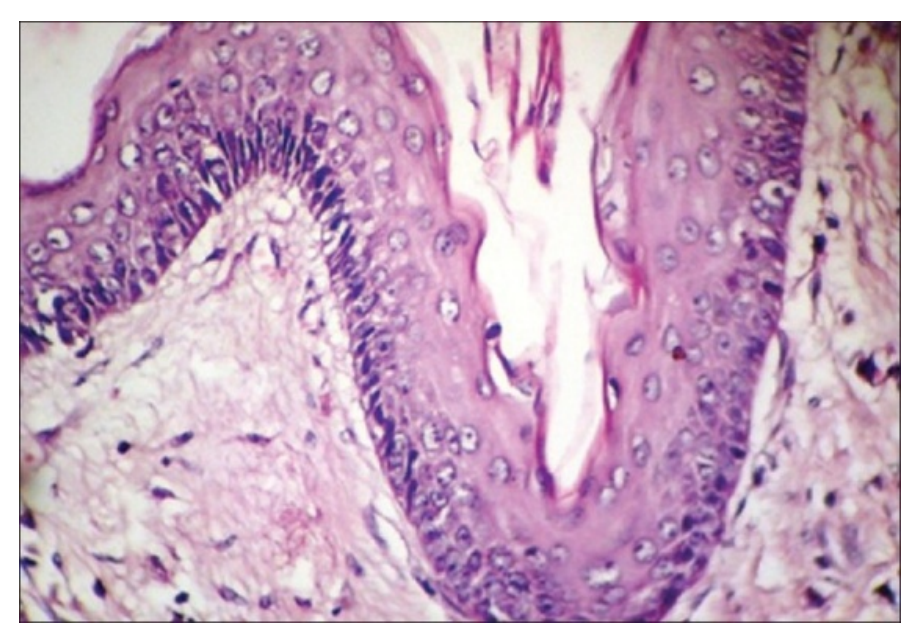

Figure 6. Keratocyst- Hyperkeratotic squamous lining

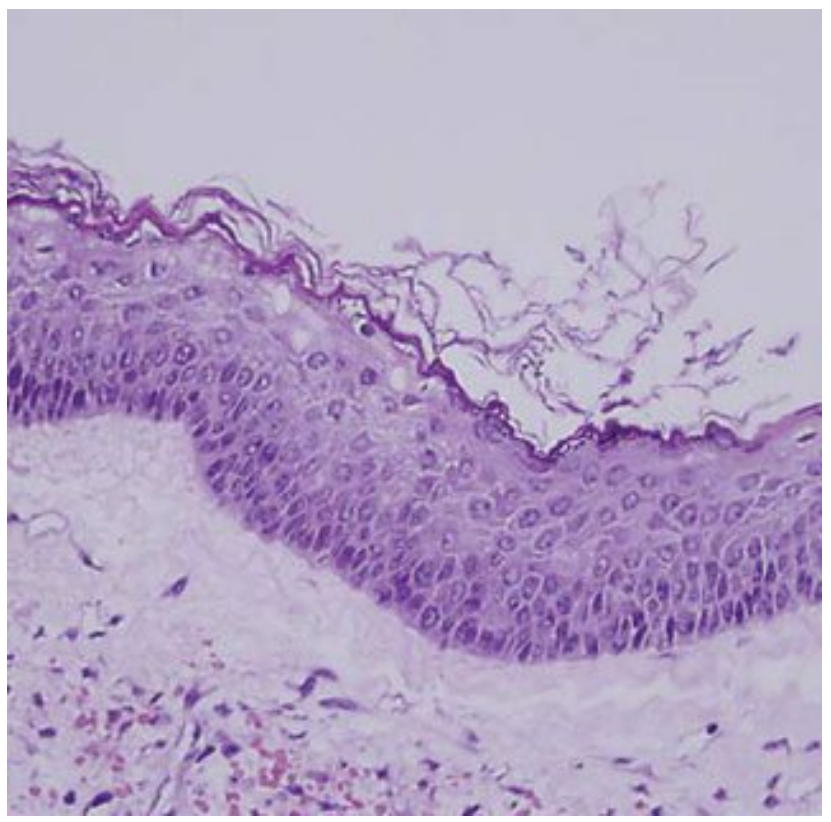

Figure 7. Keratocyst- ortho-keratinized cells with stratified keratinocytes

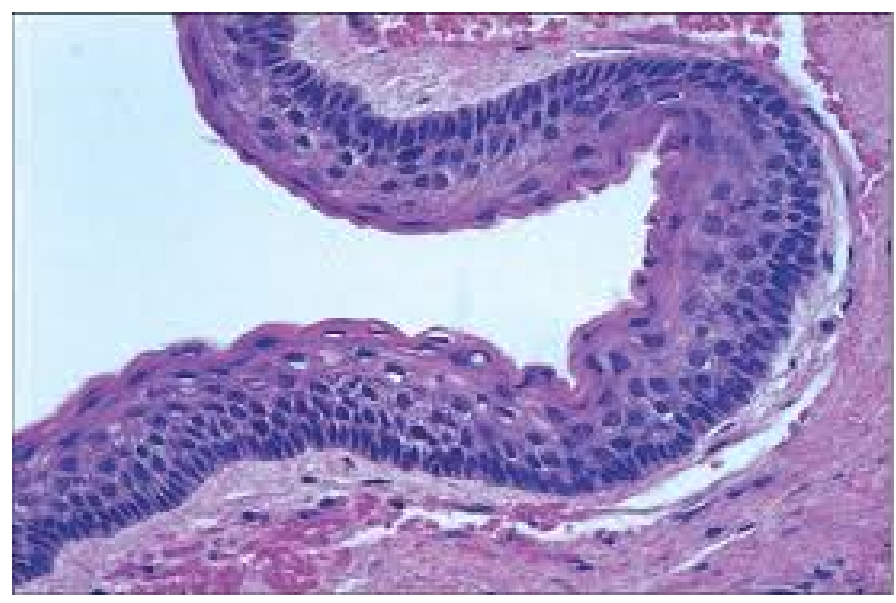

Figure 8. Keratocyst-cellular stratification with parakeratosis 


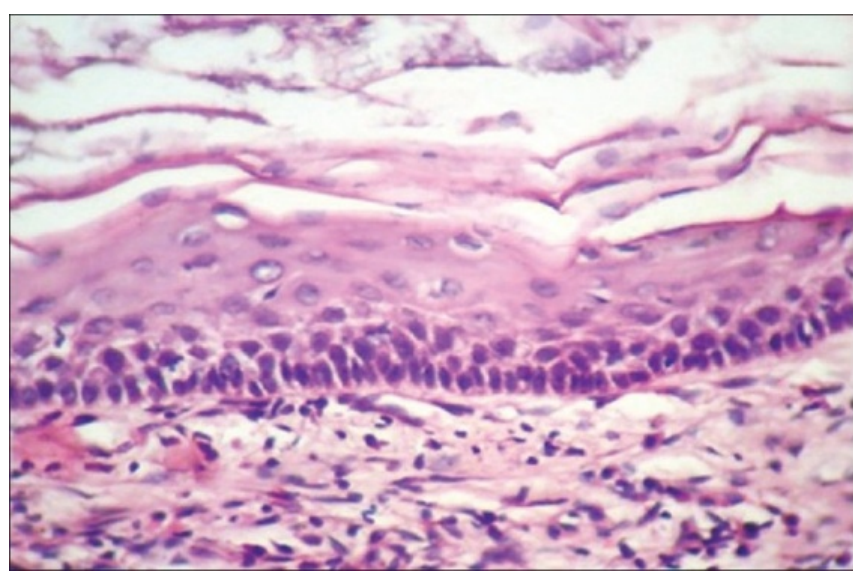

Figure 9. Keratocyst- Marked hyperkeratosis with stratification

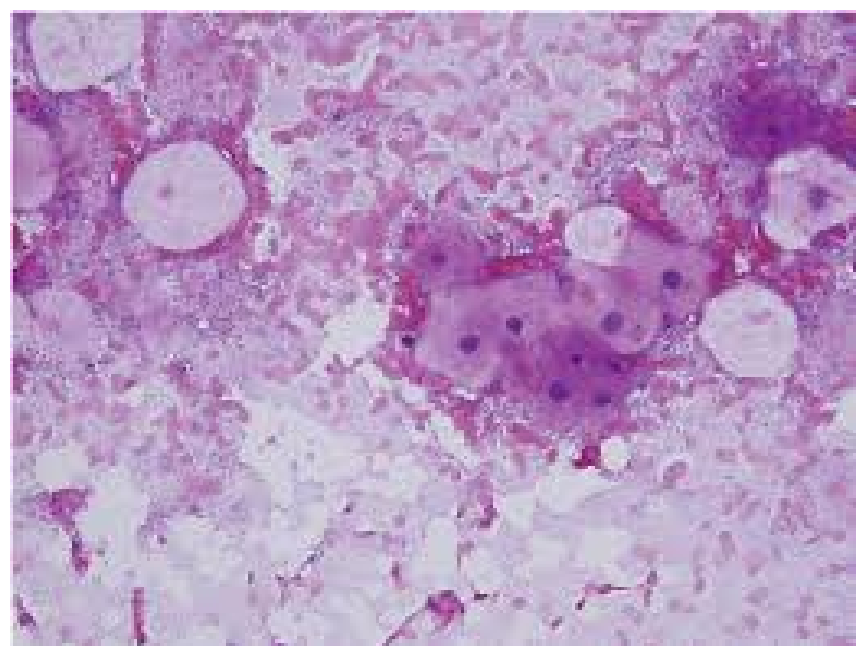

Figure 10. Keratocyst- parakeratotic cells-aspiration cytology

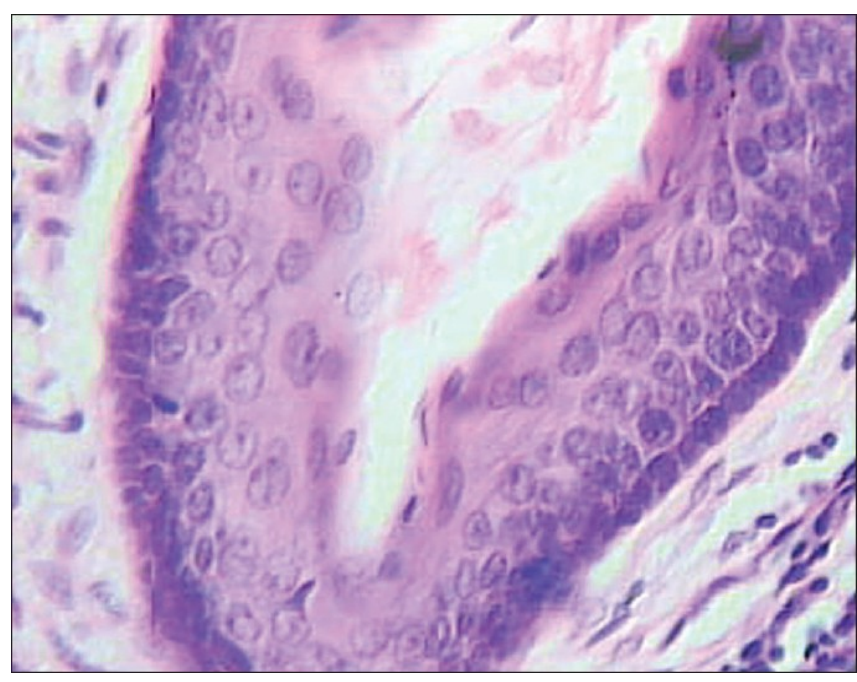

Figure 11. Keratocyst- swollen, stratified keratinocytes

\section{Preferred therapeutic strategies}

1) Surgical regimes for keratocystic odontogenic tumour (KCOT) are sub-divided into Conservative or Aggressive options [17]. CONSERVATIVE methodology is adopted, based on the specifications of the cyst and may involve an enucleation with or without an accompanying curettage or marsupialisation. The anatomical landmarks (such as the teeth) are generally preserved, especially in the younger patients. A conservative approach is appropriate at all ages, particularly with the established Nevoid Basal Cell Carcinoma Syndrome (NBCCS). AGGRESSIVE mechanics usually address the neoplasm (KCOT) and comprise of a peripheral ostectomy, chemical curettage with carnoy's solution or an en bloc resection. En bloc excision with subsequent bone graft is aggressive and a recommended surgical option. The modality is preferred in patients of Nevoid Basal Cell Carcinoma Syndrome (NBCCS), mammoth keratocystic odontogenic tumours (KCOT's) and re-occurring lesions. A situation and magnitude-based outcome may occasionally be adopted $[18,19]$. A miniature keratocyst $(\leq 1 \mathrm{~cm}$ in diameter) adjacent to the alveolar process may mandate a simple excision, whereas an enlarged keratocyst proximal to the base of the skull, with soft tissue invasion, may require a radical excision [19]. As the keratocysts are locally invasive, particularly at the skull base, the surgery may be disastrous, and a concomitant mucosal eradication may be adopted. Epithelial islands, clusters and micro-cysts may be exhibited at the mucosal junction on histology, with a potential for reappearance (Table 1) [3].

\section{Tumour relapse}

It tableis minimal with the aggressive therapy, while the conventional methodology may induce innumerable reoccurrences. Histological confirmation of the lesion (OKC), a precise follow up and a various, concordant therapeutic modalities are recommended. The estimated reoccurrences amidst the dual therapeutic modes may be significant at $15 \%$. Thus, corollaries derived may be 1) Enucleation and Carnoy's solution with or without peripheral ostectomy diminish the tumour reappearance, instead of a solitary enucleation. 2) Cryotherapy with enucleation influences the estimated reoccurrence more than a singular enucleation. 3) Solitary marsupialisation of the tumour (KCOT) elucidates a markedly increased reoccurrence, in contrast to a marsupialisation with a subsequent enucleation 4) Enucleation plus carnoy's solution or marsupialisation plus cystectomy are adequate for eradicating tumour reoccurrences, as is a comprehensive en bloc resection [3]. Enucleation of the tumour (KCOT) followed by application of carnoy's solution is an efficacious therapeutic option. Alternatively, a cystectomy subsequent to marsupialisation may be appropriate for mitigating tumour invasion and reoccurrences. Enucleation with subsequent employment of carnoy's solution may necessitate a prolonged therapy, thus patient compliance is mandatory. Individuals on this particular treatment may require an extensive irrigation of the lesion followed by a comprehensive clinical examination prior to enucleation [3].

\section{Keratocystic odontogenic tumour (KCOT)}

THE APROPOS NEOPLASM: Odontogenic keratocyst (OKC) may be considered a benign neoplasm instead of a typical cystic lesion on account of its clinical expression and may require a customized

Table 1. Therapeutic options for $k \cot [3]$.

\begin{tabular}{|l|l|}
\hline Therapeutic protocol & Estimated reoccurrence \\
\hline Enucleation & $30 \%$ \\
\hline Enucleation +Carnoy's & $9 \%$ \\
\hline Enucleation+Peripheral Ostectomy & $18 \%$ \\
\hline Enucleation +Carnoy's+ Peripheral Ostectomy & $8 \%$ \\
\hline Enucleation+ Crytherapy & $38 \%$ \\
\hline Marsupialization & $33 \%$ \\
\hline Marsupialization+ Cystectomy & $13 \%$ \\
\hline Resection & $0 \%$ \\
\hline
\end{tabular}


therapeutic schedule [20,21]. Categorization of keratocystic odontogenic tumour (KCOT) as a neoplasm by the World Health Organization (WHO) is founded on distinctive aspects 1) Clinically keratocystic odontogenic tumour (KCOT) is repetitive lesion and demonstrates local invasion. 2) Histopathology demonstrates a budding of the basal layer of the lesion with a transgression into the adjacent connective tissue (21). Mitotic figures are customary in the supra-basal layer (indicated by WHO) [3].

\section{Tumour genetics}

The tumour suppressor gene PTCH (patched), committed to the nevoid basal cell syndrome (NBCCS) and sporadic KCOT appears on chromosome 9q22. 3-q31 [22,23]. Usually PTCH conforms a receptor composite with the oncogene SMO (smoothened) for the $\mathrm{SHH}$ (sonic hedgehog) ligand. PTCH adheres to the SMO and may restrict the growth signal transduction. Attachment of the SHH to the PTCH may dispense with this requirement [24-26]. A disoriented PTCH may escalate the significance of the SMO. Nevoid basal cell carcinoma syndrome (NBCCS) and Sporadic KCOT may elucidate a "two -hit mechanism" i) Allelic depletion at $9 q 22[27,28]$ may allude to the presence of a neutralized tumour suppressor gene. The primary hit is a mutation in one allele, which may be inherited as an autosomal dominant trait, with a negligible phenotypic expression. The subsequent duplicate hit indicates the deprivation of the supplementary allele, referred to as loss of heterozygosity (LOH). In keratocystic odontogenic tumour (KCOT), this exemplifies the disorganized oncoproteins cyclin D1 and p53. LOH in the zone 9q22. 3-q31 has been described as an attribute of neoplasm in numerous epithelial tumours including the basal cell carcinoma, squamous cell carcinoma, transitional cell carcinoma [3].

\section{Connotations of tumour therapy}

Keratocystic odontogenic tumour (KCOT) is an aggressive lesion. Odontogenic keratocyst (OKC) may be categorized as a tumour by the world health organization (WHO), thus certifying that this condition should not be manipulated as a simple cyst. An aggressive approach may be suitable for diminishing the reoccurrences thereby reducing surgical trauma. En bloc resection of the jaw ensures a minimal reappearance rate, however the procedure is extreme in nature. Enucleation of the tumour (KCOT) with the application of carnoy's solution or marsupialisation followed by enucleation is the most suitable therapeutic modality. Reoccurrence is frequently co-existent with the miniature tumours (KCOT's). Nevertheless, the magnitude of the lesion may not be proportionate to the reoccurrences [29]. Enucleation and curettage are invariably followed by a tumour relapse. The overall reoccurrence rate for the entire treatment schedule is at an estimated 29\% [3]. Reoccurrences usually emerge within 2 years of the surgical manipulation. A comprehensive 5 year follow up is advisable, though the outcomes may vary due to patient compliance and time elapsed since surgery.

\section{Contemporary treatment protocols}

Cyclopamine, a plant based steroidal alkaloid prevents the cellular reaction to the $\mathrm{SHH}$ pathway. Cyclopamine may obstruct the $\mathrm{SHH}$ pathway, as determined by the oncogenic mutations, thereby producing an innately technical medium for tumour pathogenesis, comprising of a profuse $\mathrm{SHH}$ pathway [30]. The alkaloid incorporates a wild form of $\mathrm{PTCH}$ which may restrict the SMO molecule with synthetic antagonists and may contain the downstream transcription aspects of the $\mathrm{SHH}$ pathway [31]. Intra cystic injection of an SMO protein antagonist has shown a considerable promise for prospective therapeutic application.

\section{References}

1. Philipsen HP(1956) Om Keratocystdr( Kolesteratomer) and Kaeberne. Tandlaegebladet 60: $953-971$.

2. Barnes L (2005) Pathology and Genetics of head and neck tumours: Lyon IARC press: WHO Classification of tumour series.

3. Jonanthan Madras, Henry Lapointe (2008) Keratocystic Odontogenic Tumour Reclassification of the odontogenic keratocyst from cyst to tumour. JCDA 74: 1651673.

4. Browne RM (1970) The odontogenic keratocyst. Clinical aspects. Br Dent J 128: 225231. [Crossref]

5. Brannon RB (1976) The odontogenic keratocyst. A clinicopathologic study of 312 cases. Part I. Clinical features. Oral Surg Oral Med Oral Pathol 42: 54-72. [Crossref]

6. Dayan D, Buchner A, Gorsky M, Harel-Raviv M (1988) The peripheral odontogenic keratocyst. Int J Oral Maxillofac Surg 17: 81-83. [Crossref]

7. Worrall SF (1992) Recurrent odontogenic keratocyst within the temporalis muscle. $\mathrm{Br}$ J Oral Maxillofac Surg 30: 59-62. [Crossref]

8. Chehade A, Daley TD, Wysocki GP, Miller AS (1994) Peripheral odontogenic keratocyst. Oral Surg Oral Med Oral Pathol 77: 494-497. [Crossref]

9. Ide F, Shimoyama T, Horie N (2002) Peripheral odontogenic keratocyst: a report of 2 cases. J Periodontol 73: 1079-1081. [Crossref]

10. Chi AC, Owings JR Jr, Muller S (2005) Peripheral odontogenic keratocyst: report of two cases and review of the literature. Oral Surg Oral Med Oral Pathol Oral Radiol Endod 99: 71-78. [Crossref]

11. Preston RD, Narayana N (2005) Peripheral odontogenic keratocyst. J Periodontol 76 2312-2315. [Crossref]

12. Sapp JP (2004) Contemporary Oral and Maxillofacial Pathology" 2nd edition St Louis Mosby pp: 54.

13. Dominguez FV, Keszler A (1988) Comparative study of keratocysts, associated and non-associated with nevoid basal cell carcinoma syndrome. J Oral Pathol 17: 39-42. [Crossref]

14. Gorlin RJ (1987) Nevoid basal-cell carcinoma syndrome. Medicine (Baltimore) 66: 98 113. [Crossref]

15. Woolgar JA (1987) A comparative study of the clinical and histological features of recurrent an non recurrent odontogenic keratocyst. J Oral Pathol 16: 124-128.

16. Bataineh AB, al Qudah M (1998) Treatment of mandibular odontogenic keratocysts. Oral Surg Oral Med Oral Pathol Oral Radiol Endod 86: 42-47. [Crossref]

17. Morgan TA, Burton CC, Qian F (2005) A retrospective review of treatment of the odontogenic keratocyst. J Oral Maxillofac Surg 63: 635-639. [Crossref]

18. Meiselman F (1994) Surgical management of the odontogenic keratocyst: conservative approach. J Oral Maxillofac Surg 52: 960-963. [Crossref]

19. Dammer R, Niederdellmann H, Dammer P, Nuebler-Moritz M (1997) Conservative or radical treatment of keratocysts: a retrospective review. Br J Oral Maxillofac Surg 35: 46-48. [Crossref]

20. Toller P (1967) Origin and growth of cysts of the jaws. Ann R Coll Surg Engl 40: 306 336. [Crossref]

21. Ahlfors E, Larsson A, Sjögren S (1984) The odontogenic keratocyst: a benign cystic tumor? J Oral Maxillofac Surg 42: 10-19. [Crossref]

22. Hahn H, Wicking C, Zaphiropoulous PG, Gailani MR, Shanley S, et al. (1996) Mutations of the human homolog of Drosophila patched in the nevoid basal cell carcinoma syndrome. Cell 85: 841-851. [Crossref]

23. Johnson RL, Rothman AL, Xie J, Goodrich LV, Bare JW, et al. (1996) Human homolog of patched, a candidate gene for the basal cell nevus syndrome. Science 272: 16681671. [Crossref]

24. Lench NJ, Telford EA, High AS, Markham AF, Wicking C, et al. (1997) Characterisation of human patched germ line mutations in naevoid basal cell carcinoma syndrome. Hum Genet 100: 497-502. [Crossref]

25. Agaram NP, Collins BM, Barnes L, Lomago D, Aldeeb D, et al. (2004) Molecular analysis to demonstrate that odontogenic keratocysts are neoplastic. Arch Pathol Lab Med 128: 313-317. [Crossref] 
26. Barreto DC, Gomez RS, Bale AE, Boson WL, De Marco L (2000) PTCH gene mutations in odontogenic keratocysts. J Dent Res 79: 1418-1422. [Crossref]

27. Levanat S, Gorlin RJ, Fallet S, Johnson DR, Fantasia JE, et al. (1996) A two-hit model for developmental defects in Gorlin syndrome. Nat Genet 12: 85-87. [Crossref]

28. Lo Muzio (1999) Expression of cell cycle and apoptosis related proteins in a sporadic odontogenic keratocyst and keratocysts associated with nevoid basal cell carcinoma syndrome" J Dent Res 78: 1345-1353.
29. Forssell K, Forssell H, Kahnberg KE (1988) Recurrence of keratocysts. A long-term follow-up study. Int J Oral Maxillofac Surg 17: 25-28. [Crossref]

30. Taipale J, Chen JK, Cooper MK, Wang B, Mann RK, et al. (2000) Effects of oncogenic mutations in Smoothened and Patched can be reversed by cyclopamine. Nature 406: 1005-1009. [Crossref]

31. Zhang (2006) Inhibition of SHH signalling pathway, molecular treatment strategy of odontogenic keratocyst". Med Hypotheses 675: 1242-1244.

Copyright: @2018 Bajaj A. This is an open-access article distributed under the terms of the Creative Commons Attribution License, which permits unrestricted use, distribution, and reproduction in any medium, provided the original author and source are credited. 